\title{
The Cav $\beta$ subunit prevents RFP2-mediated ubiquitination and proteasomal degradation of L-type channels
}

\author{
Christophe Altier ${ }^{1,2}$, Agustin Garcia-Caballero ${ }^{1,2}$, Brett Simms ${ }^{1}$, Haitao You ${ }^{1}$, Lina Chen ${ }^{1}$, Jan Walcher ${ }^{1}$, \\ H William Tedford ${ }^{1}$, Tamara Hermosilla ${ }^{1}$ \& Gerald W Zamponi ${ }^{1}$
}

It is well established that the auxiliary $\operatorname{Cav} \beta$ subunit regulates calcium channel density in the plasma membrane, but the cellular mechanism by which this occurs has remained unclear. We found that the Cav $\beta$ subunit increased membrane expression of Cav1.2 channels by preventing the entry of the channels into the endoplasmic reticulum-associated protein degradation (ERAD) complex. Without $\operatorname{Cav} \beta, \operatorname{Cav} 1.2$ channels underwent robust ubiquitination by the RFP2 ubiquitin ligase and interacted with the ERAD complex proteins derlin-1 and p97, culminating in targeting of the channels to the proteasome for degradation. On treatment with the proteasomal inhibitor MG132, Cav $\beta$-free channels were rescued from degradation and trafficked to the plasma membrane. The coexpression of $\operatorname{Cav} \beta$ interfered with ubiquitination and targeting of the channel to the ERAD complex, thereby facilitating export from the endoplasmic reticulum and promoting expression on the cell surface. Thus, Cav $\beta$ regulates the ubiquitination and stability of the calcium channel complex.

The level of expression of voltage-gated calcium channels at the plasma membrane is a key regulator of calcium homeostasis in excitable cells, and of downstream effects such as calcium-dependent transcription ${ }^{1,2}$. Members of the high voltage-activated (HVA) calcium channel family are heteromultimeric protein complexes that contain a pore-forming $\alpha_{1}$ subunit that defines the channel subtype, plus ancillary $\alpha_{2}-\delta$ and $\beta$ subunits that not only alter the function of the $\alpha_{1}$ subunit but also regulate the trafficking of the channel complex to the plasma membrane ${ }^{3-8}$. The mammalian genome encodes four different types of Cav $\beta$ subunit that have distinct spatial and temporal expression patterns ${ }^{4-6}$. With the exception of $\operatorname{Cav} \beta_{2 a}$, these subunits are cytoplasmic proteins that physically bind to a region in the $\alpha_{1}$ subunit domain I-II linker that is highly conserved among all HVA calcium channels and is termed the alpha interaction domain (AID) ${ }^{7}$. Crystal structure data show that the $\operatorname{Cav} \beta$ subunit contains interacting $\mathrm{SH} 3$ and guanylate kinase domains, with the latter participating in high-affinity binding to the AID region ${ }^{8-10}$. The physiological consequences of this interaction are underscored by gene knockout studies showing that deletion of the $\operatorname{Cav} \beta_{1 \mathrm{a}}$ or $\operatorname{Cav} \beta_{2 \mathrm{a}}$ subunits causes embryonic lethality ${ }^{11,12}$ and by findings that a premature stop mutation in $\operatorname{Cav} \beta_{4}$ causes an epileptic phenotype in mice ${ }^{13}$.

It has been suggested that the $\operatorname{Cav} \beta$ subunit masks an endoplasmic reticulum retention signal on the Cav $2.1 \alpha_{1}$ subunit ${ }^{14}$, thereby leading to increased cell surface expression of $\mathrm{P} / \mathrm{Q}$-type channels. However, no specific endoplasmic reticulum retention motif in the AID and surrounding regions of the $\alpha_{1}$ subunit has been identified, and removing the AID motif in the I-II linker of Cav2.1 does not increase current amplitude in the absence of $\operatorname{Cav} \beta$ (ref. 15). Moreover, it is not clear whether different HVA calcium channel isoforms share common retention motifs. Here we show that Cav1.2 (L-type) calcium channels contain an endoplasmic reticulum retention motif in the proximal $\mathrm{C}$-terminal region, and we provide evidence that the $\operatorname{Cav} \beta$ subunit has a role in regulating proteasomal degradation of these channels. Our data show that the Cav $\beta$ subunit acts as a molecular switch that prevents the ubiquitination of the channels and their targeting to the ERAD complex and thereby regulates their expression at the plasma membrane.

\section{RESULTS \\ Cav $\beta$ regulates endoplasmic reticulum retention of Cav1.2}

We first performed an ELISA assay involving a Cav1.2 channel construct tagged with an extracellular hemagglutinin (HA) epitope (Fig. 1a). We compared immunoluminescence between permeabilized and nonpermeabilized cells, which allowed us to quantify the relative proportion of Cav1.2 channels that were inserted into the plasma membrane. Coexpression with the $\operatorname{Cav} \beta_{1 b}$ or $\operatorname{Cav} \beta_{2 a}$ subunit mediated a significant increase in the fraction of Cav1.2 channels at the cell surface (Fig. 1a and data not shown). This was confirmed by HA-immunoreactivity of nonpermeabilized cells (Fig. 1b) and surface biotinylation experiments (Fig. 1c). Nonetheless, channel targeting to the plasma membrane remained incomplete even in the presence of $\operatorname{Cav} \beta_{1 b}$, indicating that there was a substantial pool of Cav1.2 channels in cytoplasmic compartments (Fig. 1a and Supplementary Fig. 1). Coexpression of the $\operatorname{Cav} \beta_{1 b}$ subunit

${ }^{1}$ Department of Physiology and Pharmacology, Hotchkiss Brain Institute, University of Calgary, Calgary, Alberta, Canada. ${ }^{2}$ These authors contributed equally to this work. Correspondence should be addressed to G.W.Z. (zamponi@ucalgary.ca).

Received 10 August; accepted 12 November; published online 26 December 2010; doi:10.1038/nn.2712 
a

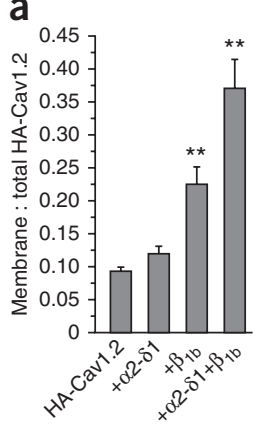

b

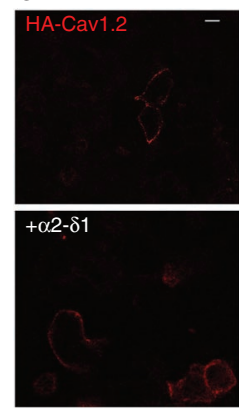

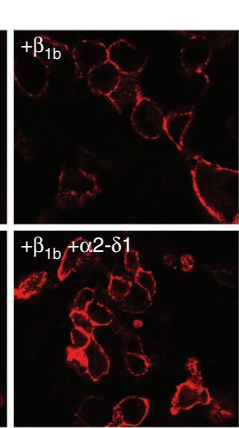

C

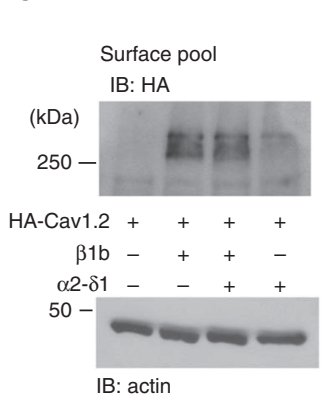

d

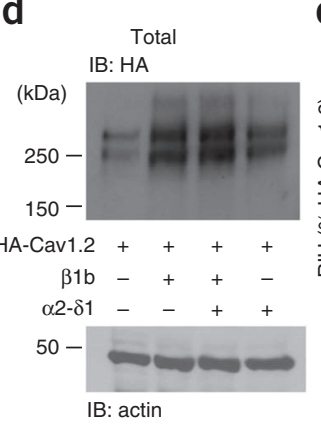

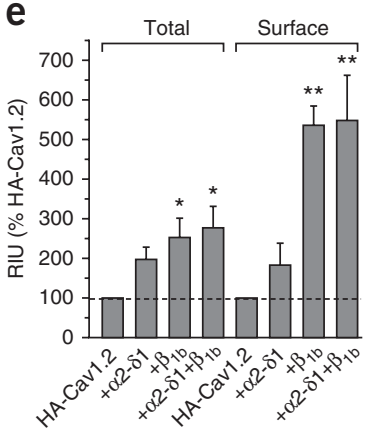

Figure 1 Cav $\beta$ subunits increase surface and total expression of Cav1.2 channels. (a) Relative cell surface expression of HA-Cav1.2 channels measured by immunoluminometry in the presence of different subunits ( $P<0.01$; ANOVA). Luminometry readings from nonpermeabilized cells (membrane) were normalized to those of permeabilized cells (total) to yield the fraction of channels at the cell surface. We conducted 3-5 ELISA assays for each condition. (b) Representative confocal microscope images of nonpermeabilized tsA-201 cells expressing the HA-Cav1.2 channel alone, or in combination with $\operatorname{Cav} \beta_{1 \mathrm{~b}}, \operatorname{Cav}_{2}-\delta_{1}, \operatorname{Cav} \beta_{1 \mathrm{~b}}+\mathrm{Cav} \alpha_{2}-\delta_{1}$. Scale bar, $10 \mu \mathrm{m}$. (c) Western blot of surface-biotinylated HA-Cav1.2 transfected into tsA-201 cells, coexpressed with Cav $\alpha_{2}-\delta_{1}$ or Cav $\beta_{1 b}$. Lower panel, corresponding actin control. (d) Western blot of total HA-Cav1.2 transfected into tsA-201 cells, coexpressed with $\operatorname{Cav}_{2}-\delta_{1}$ or $\operatorname{Cav} \beta_{1 b}$. (e) Quantification of relative integrated density values from western blots such as in panel c (surface) and d (total). Each HA-Cav1.2 band was corrected for the intensity of the actin control, and then normalized to the values obtained in the absence of ancillary subunits to facilitate comparison. Data from three experiments are included in the bar chart (*P<0.05, ** $P<0.01$; ANOVA). Error bars show s.e.m.

also increased the total pool of HA-Cav1.2 channels (Fig. 1d,e), indicating that $\mathrm{Cav} \beta$ either promotes the expression of Cav1.2 or prevents protein degradation. The $\operatorname{Cav} \beta$ subunit-mediated increase in total Cav1.2 expression and the enhanced membrane trafficking give rise to a substantial increase in channel protein at the cell surface (Fig. 1b,e), thereby accounting for the known effect of $\operatorname{Cav} \beta$ subunits on whole-cell current densities.

The reduced surface expression of Cav1.2 in the absence of the Cav $\beta$ subunit could in principle be due to retention of the $\alpha_{1}$ subunit in the endoplasmic reticulum. To identify putative retention motifs in the channel sequence, we created a series of CD4 constructs fused to the various intracellular regions of Cav1.2 (and for comparison Cav2.2 N-type) channels (Fig. 2a). These constructs were expressed in tsA-201 cells and their expression monitored initially by immunostaining and confocal microscopy. In a control experiment, coexpression of

Figure 2 Determinants of endoplasmic reticulum retention of intracelllular regions of HVA calcium channels. (a) Schematic representation of the different constructs of intracellular regions of Cav1.2 and Cav2.2, fused to CD4 membrane receptor. Cter, C terminus; Nter, $\mathrm{N}$ terminus. (b) Confocal images representing the translocation of $\operatorname{Cav} \beta_{1 \mathrm{~b}}$-YFP to the membrane mediated by CD4-I-II linker of Cav1.2. Note that the CD4-I-II linker of Cav3.2 does not translocate $\operatorname{Cav} \beta_{1 \mathrm{~b}}$-YFP. Scale bars, $10 \mu \mathrm{m}$. (c) Surface expression of intracellular linkers of Cav1.2 fused to the CD4 transmembrane region, measured by immunoluminometry. (d) Surface expression of intracellular linkers of Cav2.2 fused to CD4 transmembrane regions $\left({ }^{*} P<0.05\right.$; one-way ANOVA followed by Tukey's multiple comparison tests). Error bars show s.e.m.; $n=3-5$ ELISA assays for each condition. Fractional surface expression values for the fusion constructs were normalized to those of the cell surface expression marker CD4-AA in each transfection (see Online Methods). the domain I-II linker CD4 construct resulted in the translocation of the $\operatorname{Cav} \beta_{1 b}$ subunit from the cytoplasm to the plasma membrane (Fig. 2b), indicating that the ability of the I-II linker region to interact with the $\operatorname{Cav} \beta$ subunit was preserved in the CD4 fusion construct. By contrast, a CD4 construct of the domain I-II linker of Cav3.2 T-type channels (which do not interact with $\operatorname{Cav} \beta$ ) did not mediate such translocation (Fig. 2b), nor did other regions of the Cav1.2 channels that cannot bind $\operatorname{Cav} \beta$ (Supplementary Fig. 2a). Next, we examined the surface expression of the entire set of CD4 constructs using immunoluminometry. We used the expression of a

\section{a}
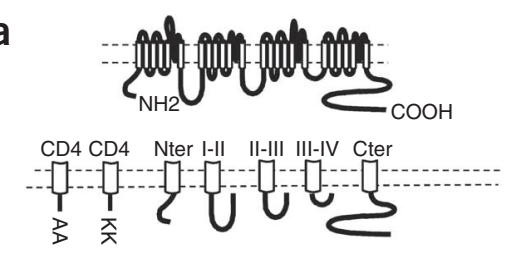

Cav1.2

Cav2.2
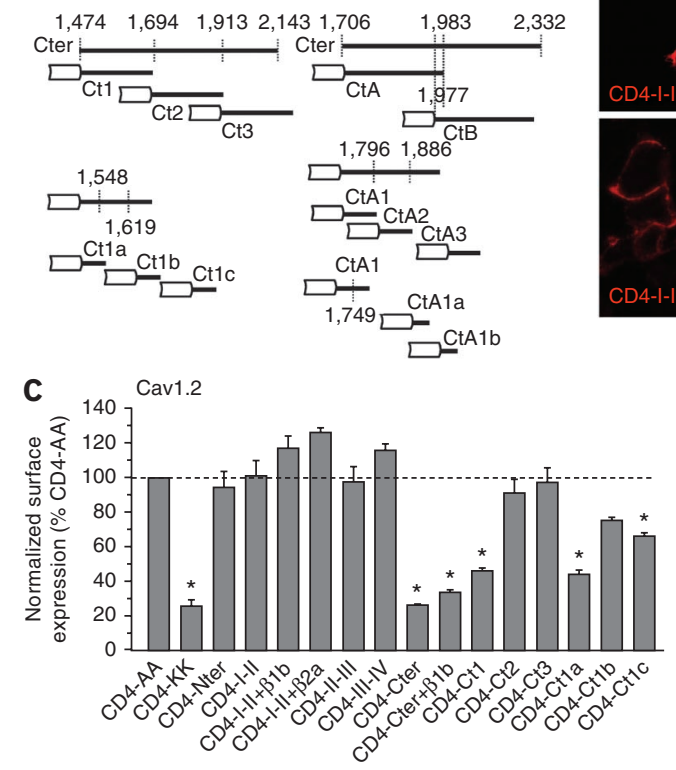
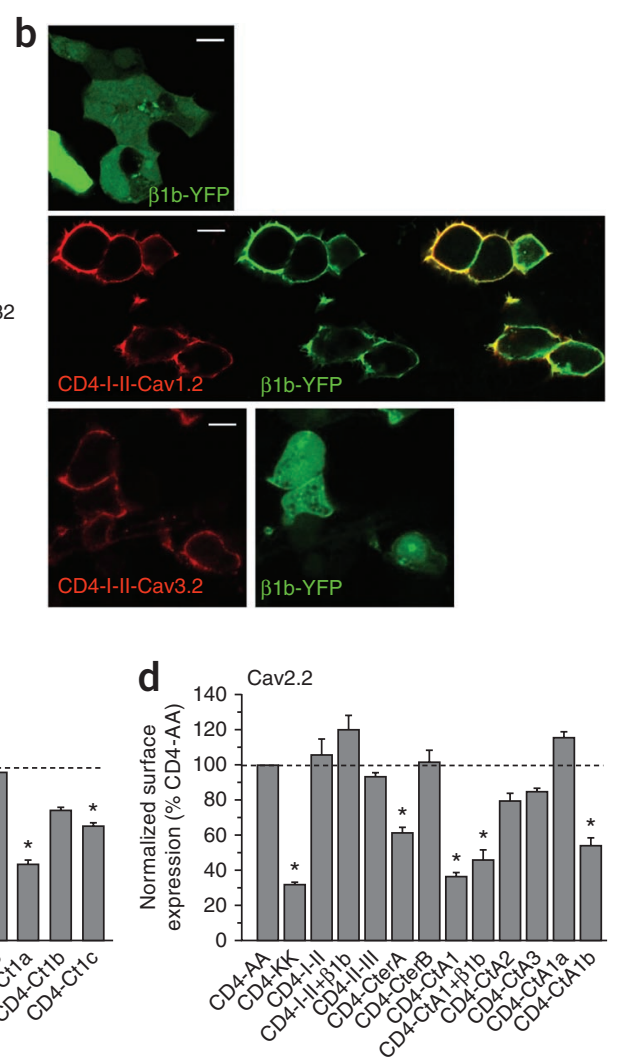
Figure 3 MG132 and Cav $\beta$ both increase surface expression of Cav1.2 channels. (a) Confocal images of nonpermeabilized tsA-201 cells transfected and stained for HA-Cav1.2 after treatment with $5 \mu \mathrm{M}$ of MG132 (right). Scale bars, $50 \mu \mathrm{m}$. (b) Western blot of total HA-Cav1.2 transfected into tsA-201 cells, coexpressed with $\operatorname{Cav} \alpha_{2}-\delta_{1}$ or $\operatorname{Cav} \beta_{1 b}$ with or without treatment with the proteasome inhibitor MG132 $(5 \mu \mathrm{M})$. Lower panel, corresponding actin control (input 5\%). (c) Quantification of relative integrated density values from each band of the western blot in $\mathbf{b}$ with or without MG132. Intensity of HA-Cav1.2 was normalized to that of the actin band. Data from five experiments are included $(* * P<0.01$; ANOVA). Error bars show s.e.m.

positive control construct for sorting (CD4-AA) for normalization, and data were compared to the surface expression levels of a 'retention control' (CD4-KK) ${ }^{16,17}$. The $\mathrm{N}$ terminus, domain I-II linker, domain II-III linker and domain III-IV linker regions of the channel were trafficked to the plasma membrane as effectively as CD4-AA (Fig. 2c,d). Although coexpression of the $\operatorname{Cav} \beta_{1 b}$ or $\operatorname{Cav} \beta_{2 a}$ subunits seemed to mediate a small increase in the membrane trafficking of the domain III linker region, this was not statistically significant, and was eclipsed in magnitude by the effect of $\operatorname{Cav} \beta$ on the membrane expression of full-length Cav1.2 (Fig. 1). These data indicate that the Cav1.2 domain I-II linker does not contain an endoplasmic reticulum retention signal (Fig. 2c,d and Supplementary Fig. 2b). By contrast, CD4 constructs corresponding to either the entire $\mathrm{C}$ terminus or the proximal third of this region showed reduced surface expression (Fig. 2c).

Within the proximal C terminus region of Cav1.2, two distinct subregions showed endoplasmic reticulum retention. We obtained qualitatively similar results with the Cav2.2 C terminus (Fig. 2d) with the exception that it contained only one endoplasmic reticulum retention motif; nonetheless, this indicates that the retention mechanism may be conserved among N-type and L-type channels (Supplementary Fig. 3). Retention of the Cav1.2 or Cav2.2 C terminus in the endoplasmic reticulum could not be reversed upon coexpression of the $\operatorname{Cav} \beta_{1 b}$ or $\operatorname{Cav} \beta_{2 a}$ subunit (Fig. $2 \mathbf{c}, \mathbf{d}$ ), consistent with the notion that the Cav $\beta$ subunit does not bind to this region of the channel. These findings contrast with results obtained with Cav2.1 constructs in which the I-II linker rather than the $\mathrm{C}$ terminus was retained, and Cav $\beta$ subunit coexpression counteracted this endoplasmic reticulum retention (Supplementary Fig. 4), in agreement with previous suggestions that $\operatorname{Cav} \beta$ directly occludes the Cav2.1 retention motif ${ }^{14}$. Together, our data indicate that calcium channels can be subject to at least two distinct mechanisms that regulate export from the endoplasmic reticulum.

\section{Cav $\beta$-free channels are targeted to the proteasome}

Although the idea that the $\operatorname{Cav} \beta$ subunit facilitates channel export from the endoplasmic reticulum fits with the observed increase in cell surface expression of the channels, it is unlikely to account for the observed increase in total Cav1.2 protein (Fig. 1e). One possibility is that the $\operatorname{Cav} \beta$ subunit reduces channel turnover and targeting to endocytic compartments. However, in the absence of Cav $\beta$ there was no colocalization of HA-Cav1.2 with markers for early or late endosomes or with LysoTracker, which suggests that the reduced membrane expression observed in the absence of $\operatorname{Cav} \beta$ was not mediated by enhanced internalization of $\operatorname{Cav} \beta$-free channels from the plasma membrane (Supplementary Fig. 5). Alternatively, the Cav $\beta$ subunit might prevent channel degradation in the proteasome. To determine whether Cav1.2 channels were targeted to the proteasome in the absence of the $\operatorname{Cav} \beta$ subunit, we examined the effect of the proteasome inhibitor MG132 under various transfection conditions (Fig. 3). In cells expressing HA-Cav1.2 alone, MG132

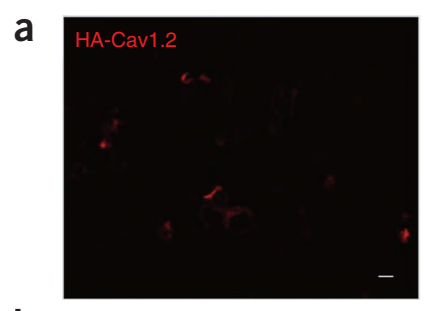

b
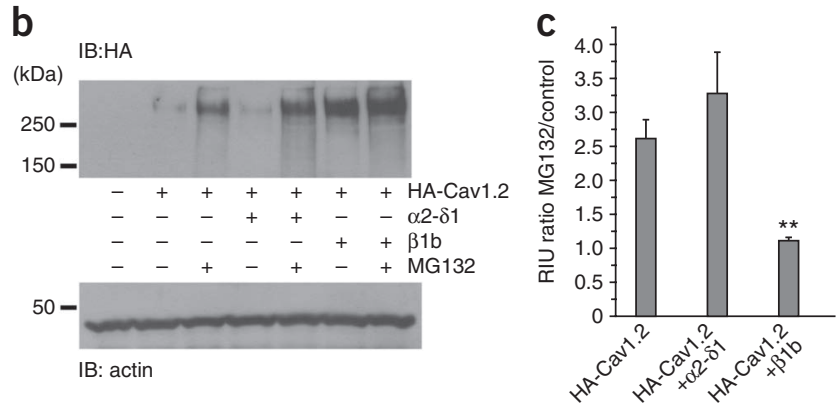

treatment markedly increased plasma membrane expression of the channel (Fig. 3a) and decreased the effect of Cav $\beta$ on HA-Cav1.2 surface expression from $2.71 \pm 0.05$-fold to $1.59 \pm 0.015$-fold $(n=6$, ${ }^{*} P<0.01$; see also Supplementary Fig. 6). Furthermore, MG132 increased total Cav1.2 channel protein when expressed alone or with the $\operatorname{Cav} \alpha_{2}-\delta$ subunit, but not in the presence of $\operatorname{Cav} \beta$ (Fig. 3b,c). Analysis of the subcellular localization of HA-Cav1.2 showed that the channel alone did not colocalize with the membrane marker construct CD4-AA, whereas membrane colocalization was increased upon either coexpression of the $\operatorname{Cav} \beta$ subunit or treatment with MG132 (Fig. 4a-d). Conversely, colocalization with a marker of the endoplasmic reticulum and perinuclear region (CD4-KK) was decreased (Supplementary Fig. 6).

Together, our results indicate that the $\operatorname{Cav} \beta$ subunit stabilizes Cav1.2 channels and increases total Cav1.2 protein by preventing proteasomal degradation of the channels. Furthermore, our data suggest that blocking the proteasomal degradation pathway leads to cell surface targeting of Cav1.2 channels in the absence of $\operatorname{Cav} \beta$.

\section{Ubiquitinated Cav1.2 channels enter the ERAD complex}

Before proteasomal degradation, misfolded and unassembled membrane proteins are recognized and retrotranslocated into the cytosol where they pass though the 'quality control' system, ERAD. A protein complex that includes derlin-1 and p97 is responsible for recognizing misfolded proteins in yeast and for protein degradation mediated by viruses in host cells, and has been linked to the degradation of cystic fibrosis transmembrane conductance regulator (CFTR) channel mutants in mammalian cells ${ }^{18-21}$. To determine whether Cav1.2 channels use a similar degradation pathway, we examined the ability of Cav1.2 channels to associate with these ERAD signaling proteins. Both derlin-1 and p97 could be detected by western blot analysis in tsA-201 cell lysate (not shown) and were found to co-immunoprecipitate with recombinant and native Cav1.2 channels (Fig. 4e). Coexpression of Cav $\beta$ subunits in tsA-201 cells significantly reduced the co-immunopreciptation of derlin-1 and p97 with the channel (Fig. 4f,g) when the data were normalized to total Cav1.2 channel expression. However, the association of derlin-1 and p97 with the channel was not completely eliminated in the presence of $\operatorname{Cav} \beta$. This could be due to one of two mechanisms. First, the Cav $\beta$ subunit may incompletely prevent the association of these proteins with a given channel. Alternatively (and consistent with the observations in Supplementary Fig. 1), 
a

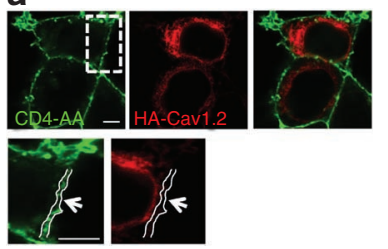

b

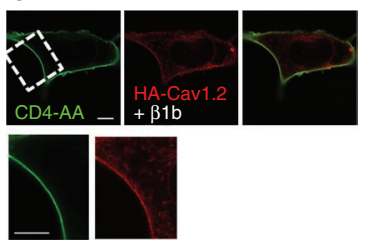

C
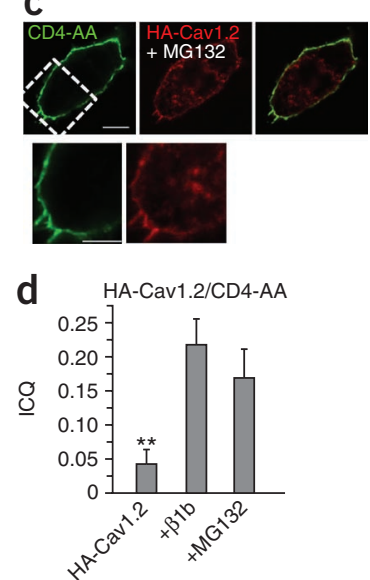

e

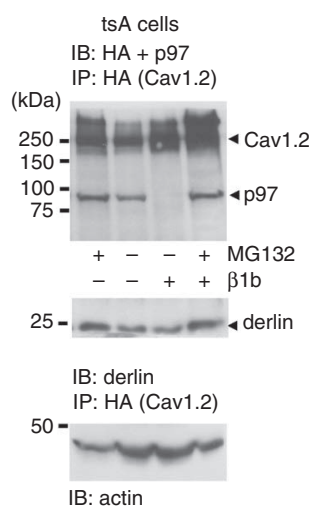

f

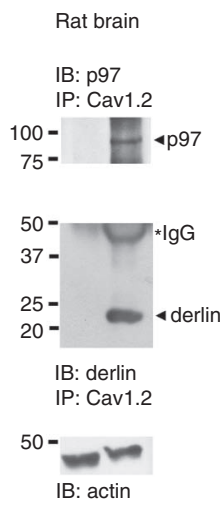

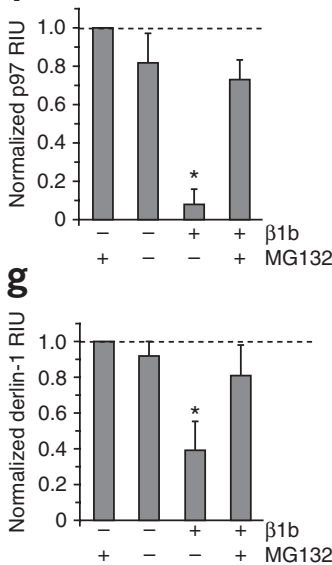

Figure 4 Cav1.2 channels interact with the ERAD protein complex in the absence of Cav $\beta$. (a-c) Confocal images of permeabilized tsA-201 cells transfected and stained for the membrane marker CD4-AA (green) and HA-Cav1.2 (red), coexpressed with Cav $\beta$ (b) or after overnight treatment with $5 \mu$ M of MG132 (c). Inset images correspond to areas outlined by white dashed boxes. Scale bars represent $10 \mu \mathrm{m}$ in main images and $5 \mu \mathrm{m}$ in magnified images. Similar data were obtained from multiple transfections. In a, there is no HA-Cav1.2 label in the membrane region (arrows). (d) Summary of the intensity correlation quotients (ICQ) for the imaging conditions. The ICQ was measured for multiple transfections and denotes colocalization between HA-Cav1.2 and CD4-AA in the presence but not the absence of $\operatorname{Cav} \beta_{1 \mathrm{~b}}\left({ }^{* *} P<0.01\right.$; ANOVA). (e) Left, co-immunoprecipitations of Cav1.2 and endogenous p97 (top) or derlin-1 (bottom) from transfected tsA-201 cells (left) or rat brain homogenate (right). In tsA-201 cells, Cav1.2 channels contained the HA tag, and the western blot was also probed for HA immunoreactivity. (f) Quantification of the relative integrated density value (RIU) from each band of co-immunoprecipitated p97 from tsA-201 cells. To account for variation in Cav1.2 expression, the RIU ratio between p97 and HACav1.2 was calculated, and the data were subsequently normalized to the condition of HA-Cav1.2+MG132. Data from three experiments are included in the bar chart ( ${ }^{*} P<0.05$; ANOVA). (g) As in $\mathbf{f}$, but for derlin-1 rather than p97. Data from three experiments are included in the bar chart (* $P<0.05$; ANOVA). Error bars show s.e.m.

even upon $\operatorname{Cav} \beta$ subunit coexpression, there could be a pool of $\operatorname{Cav} \beta$ free channels that are associated with derlin-1 and p97. If so, treatment of the cells with MG132 should increase the pool of Cav $\beta$-free channels and thus the overall fraction of channels that are associated with derlin-1 and p97, and this seems to be the case (Fig. $\mathbf{4 e - g}$ ). Collectively, these data suggest that the $\operatorname{Cav} \beta$ subunit acts as a gatekeeper for entry of Cav1.2 channels into the ERAD complex.
In the ERAD complex, misfolded and misassembled proteins can also be subject to ubiquitination in the endoplasmic reticu$\operatorname{lum}^{22,23}$ which normally precedes the initiation of the proteasome pathway. Indeed, p97 is thought primarily to bind to ubiquitinated proteins. We therefore investigated the ubiquitination of HACav1.2 channels in the absence and presence of $\operatorname{Cav} \beta$ subunits in tsA-201 cells. We blocked channel degradation with MG132,
Figure 5 The $\operatorname{Cav} \beta$ subunit prevents ubiquitination of Cav1.2 channels. (a) Western blot of HA-Cav1.2 and ubiquitinated Cav1.2 with or without treatment with MG132. Channels were immunoprecipitated with $\mathrm{HA}$ antibody. Membranes blotted for HA were stripped and blotted with ubiquitin antibody. (b) Western blot showing ubiquitination of immunoprecipitated HA-Cav1. 2 channels, in tsA-201 cells transfected with or without $\operatorname{Cav} \beta_{1 b}$ and treated with MG132. Membranes were probed for ubiquitin (upper) and actin (lower). (c) As in $\mathbf{b}$ but using the Cav $\beta$ binding-deficient Cav1.2 ${ }_{\text {W440A }}$ mutant. Also included is a representative coimmunoprecipitation experiment showing that, unlike the wild-type channel, the Cav1.2 ${ }_{\text {W440A }}$ channel does not associate with a flag-tagged Cav $\beta_{2 a}$ construct. (d) Western blot showing ubiquitination of immunoprecipitated Cav1.2 channels in CAD cells. Membranes were probed for ubiquitin (upper) and actin (lower).

(e) Left, western blot of Cav1.2 from cultured rat hippocampal neurons. Neurons were incubated with MG132 overnight. Lysates were immunoprecipitated with Cav1.2 antibody. Right, membranes blotted for Cav1.2 were stripped and blotted with ubiquitin antibody. a
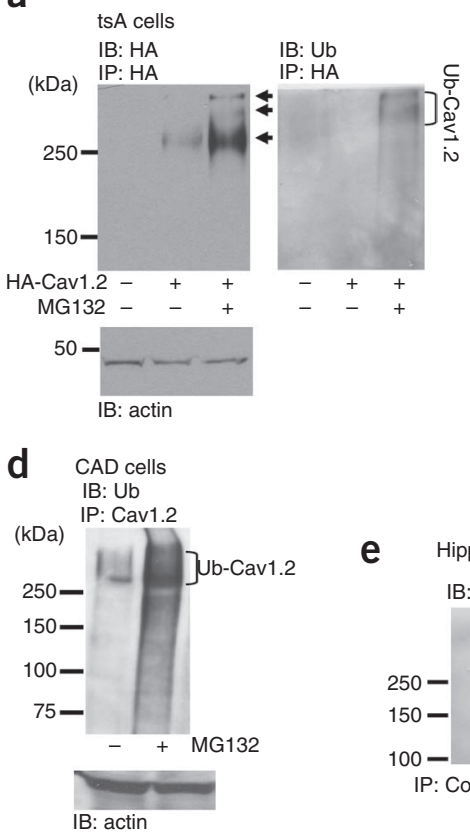

IB: actin

e
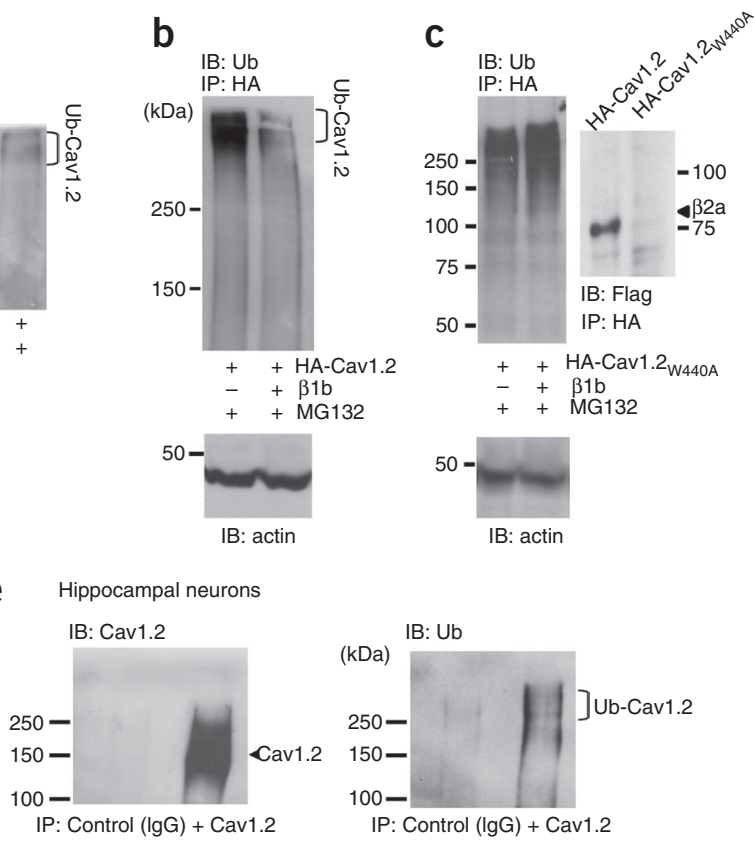

IB: Ub

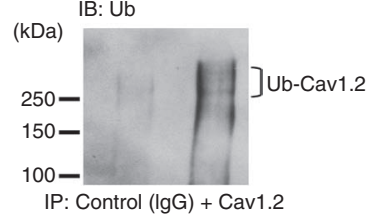


immunoprecipitated Cav1.2 channels with an HA antibody and analyzed immunoprecipitates by western blots using specific ubiquitin antibodies. Western blots of tsA-201 cell lysates expressing HA-Cav1.2 in the absence of $\operatorname{Cav} \beta$ revealed high molecular weight bands that were also immunoreactive for ubiquitin (Fig. 5a). Ubiquitin immunoreactivity was reduced upon coexpression of the Cav $\beta_{1 \mathrm{~b}}$ subunit (Fig. 5b), despite the fact that there was a large increase in total Cav1.2 protein (Fig. 1e). Reminiscent of our findings with derlin-1 and $\mathrm{p} 97$, the $\operatorname{Cav} \beta$ subunit did not completely prevent ubiquitination, again consistent with the existence of a fraction of Cav $\beta$-free channels. Ubiquitination was also observed when cells were transfected with Hisubiquitin (Supplementary Fig. 7a). The $\operatorname{Cav} \beta_{2 a}$ subunit was equally effective at preventing ubiquitination of the Cav1.2 channel, as shown by western blot even at extended film exposures (Supplementary Fig. 7b). Unlike Cav1.2 channels, there was little ubiquitination of Cav2.1 in the absence of the Cav $\beta$ subunit (Supplementary Fig. 7c), consistent with the idea that $\operatorname{Cav} \beta$ regulates Cav2.1 channel expression by a different mechanism (Supplementary Fig. 4).

We also examined the ubiquitination of a mutant Cav1.2 calcium channel construct that cannot associate with the Cav $\beta$ subunit (HACav1.2 $\left.{ }_{\text {W440A }}\right)^{24,25}$. The mutant channel showed robust ubiquitination irrespective of the coexpression of $\operatorname{Cav} \beta_{1 \mathrm{~b}}$ (Fig. 5c), indicating that the effect of $\operatorname{Cav} \beta$ on the ubiquitination of wild-type Cav1.2 is due to its binding interaction with the channel, rather than simply its presence in the cell. Finally, we examined the ubiquitination of native Cav1.2 channels. In the neuronal cell line CAD, a population of endogenous Cav1.2 channels was ubiquitinated, and ubiquitinated channels accumulated when we blocked proteasomal degradation (Fig. 5d). Native channels in rat hippocampal neurons also showed tonic ubiquitination (Fig. 5e). Together, our data support a mechanism in which the Cav $\beta$ subunit antagonizes the ubiquitination of Cav1.2 channels.

\section{RFP2 mediates ubiquitination of Cav1.2}

Ubiquitination of target proteins typically involves the transfer of ubiquitin from an E2 ubiquitin conjugating enzyme by an E3 ubiquitin ligase. The mammalian genome expresses more than $600 \mathrm{E} 3$ ubiquitin ligases with different localizations and functions ${ }^{26}$; among these, ligases such as Nedd 4 have been implicated in the internalization of channels such as $\mathrm{ENaC}$ and $\mathrm{ClC}-5$ whereas ligases associated with the ERAD complex have been linked to proteasomal degradation of channels such as CFTR $^{23}$. Consistent with involvement of the ERAD complex in regulation of Cav1.2, we found no association of Nedd 4 with the L-type channel (not shown). We then knocked down a subset of canonical endoplasmic reticulum-localized ubiquitin ligases using short hairpin RNAs (shRNAs) and examined the ubiquitination of Cav1.2 channels. Knockdown of RFP2, an E3 ubiquitin ligase ${ }^{27}$, resulted in a marked reduction in Cav1.2 channel ubiquitination, whereas knockdown of the Hrd1 or gp78 ligases (Fig. 6a-c) or of MARCH6 (data not shown) did not significantly reduce ubiquitination of the channel. We then tested whether RFP2 could associate with Cav1.2 channels. RFP2 co-immunoprecipitated with endogenous Cav1.2 channels in CAD cells (Fig. 6d). Similarly, RFP2 and native Cav1.2 channels could be co-immunoprecipitated from rat brain homogenate (Fig. 6e). Finally, YFP-tagged RFP2 could be co-immunoprecipitated from tsA-201 cells (Fig. 6f). These results indicate that RFP2 can associate with Cav1.2 channels. To further implicate RFP2, we

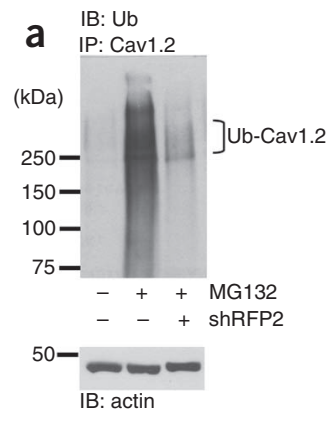

Figure 6 Cav 1.2 channels associate with the RING domain ubiquitin ligase RFP2. (a) Western blot of ubiquitinated Cav1.2 (2nd lane) or Cav1.2 transfected with shRNA for RFP2 (3rd lane). Membranes were probed for actin (lower). (b) Western blot of ubiquitinated Cav1.2 from immunoprecipitates of Cav1.2 from CAD cells treated with MG132 (10 $\mu \mathrm{M})$ and transfected with different shRNA

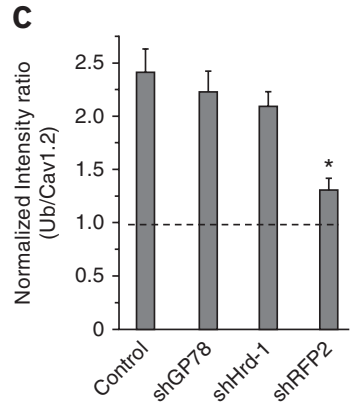

d

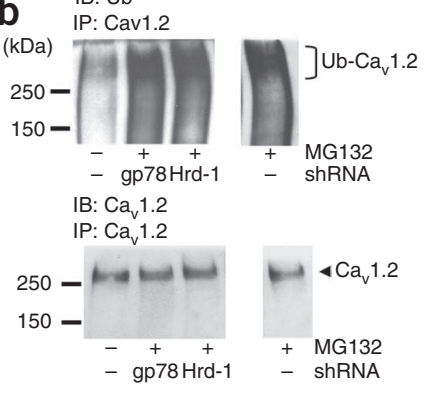

e

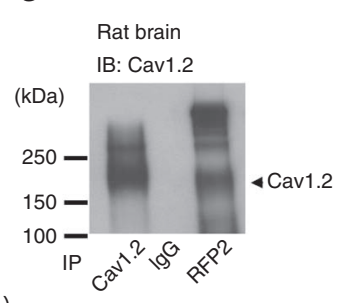

f

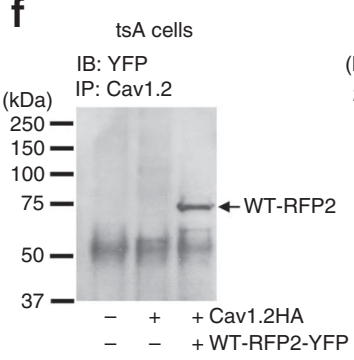

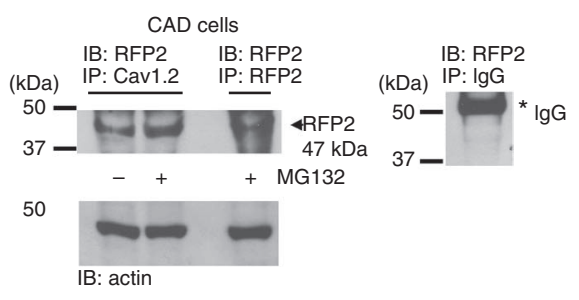

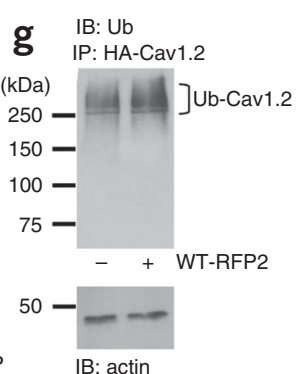

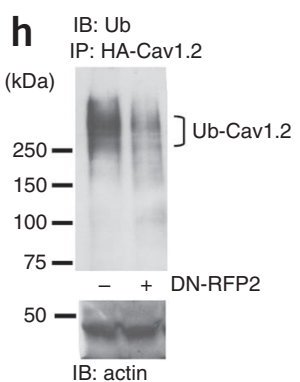

plasmids (gp78 and Hrd-1). Membranes were also probed for Cav1.2 (lower). (c) Densitometric analysis of ubiquitinated Cav1.2 channels (a,b) in relation to total Cav1.2 protein, for different conditions of shRNA transfection. Data from three experiments are included $\left({ }^{*} P<0.05 ;\right.$ ANOVA). Error bars show s.e.m. (d) Co-immunoprecipitation experiments from CAD cells. Immunoprecipitates of Cav1.2, RFP2 and control (IgG) were run on SDSPAGE and membranes were blotted with RFP2 antibody. Actin was run as loading control (bottom). RPF2 was detected at a molecular weight of 47 $\mathrm{kDa}$ and control IgG runs above $50 \mathrm{kDa}$ (right). (e) Co-immunoprecipitation experiments from rat brain homogenates in the presence of MG132. Immunoprecipitates of Cav1.2, control (IgG) and RFP2 were run on SDS-PAGE and blotted with Cav1.2 antibody. Consistent with ubiquitination, higher molecular weight Cav1.2 bands were present when channels were precipitated with RFP2 antibodies. (f) Co-immunoprecipitation experiments from tsA-201 cells transfected with HA-Cav1.2 or HA-Cav1.2 + WT-RFP2-YFP in the presence of MG132. Immunoprecipitates of HA-Cav1.2 were run on SDS-PAGE and blotted with YFP antibody. (h) Western blot of ubiquitinated HA-Cav1.2 from immunoprecipitates of HA-Cav1.2 transfected into tsA-201 cells in the absence or the presence of WT-RFP2. Experiments were conducted in the presence of MG132. Actin was run as loading control (bottom). (g) Western blot of ubiquitinated HA-Cav1.2 from immunoprecipitates of HA-Cav1.2 transfected in tsA-201 cells in the absence or the presence of DNRFP2. Experiments were conducted with MG132. Actin was run as loading control (bottom). 
Figure 7 Dominant-negative RFP2 increases barium current density, and enhances surface expression of Cav1.2 channels in hippocampal neurons. (a) Whole-cell current-voltage relations from CAD cells under control conditions, or when transfected with DN-RFP2. Error bars show s.e.m. (b) Confocal image obtained from a cultured hippocampal neuron transfected with eGFP and HA-Cav1.2 and immunostained with $\mathrm{HA}$ antibody. Lower panel, merged image. $(\mathbf{c}, \mathbf{d})$ Higher magnifications image of a neuronal process expressing eGFP and labeled for HA-Cav1.2, with WT-RFP2 or DN-RFP2. Scale bars, $10 \mu \mathrm{m}$; similar data were obtained from multiple transfections.

examined the effect of either wild-type RFP2 (WT-RFP2; Fig. 6g) or dominant negative RFP2 (DN-RFP2; Fig. 6h) on the degree of ubiquitination of Cav1.2 channels in tsA-201 cells. Expression of the WT-RFP2 construct mediated a small (22\%) increase in Cav1.2 ubiquitination. Conversely, the extent of ubiquitination observed in the presence of the DN-RFP2 construct (Fig. 6h) was reduced by $52 \%$ relative to control, which confirms that the RFP2 ligase is involved in the ubiquitination of the Cav1.2 channel.

To determine the functional consequences of RFP2-mediated ubiquitination, we first examined the effects of the WT- and DNRFP2 constructs on barium current densities in CAD cells (Fig. 7a). Coexpression of DN-RFP2 resulted in a significant increase in wholecell current densities from $2.39 \pm 0.22 \mathrm{pA} \mathrm{pF}^{-1}$ to $5.39 \pm 0.55 \mathrm{pA} \mathrm{pF}^{-1}$ $(P<0.001)$, consistent with the biochemical data (Figs. 5d and $\mathbf{6 h})$. Coexpression of WT-RFP2 had no effect (data not shown), which indicates that there was sufficient endogenous RFP2 activity (Fig. 5d). As CAD cells do not express a pure population of L-type currents, we carried out a series of analogous experiments in tsA-201 cells that were transfected with Cav1.2 $\left(+\operatorname{Cav} \alpha_{2}-\delta\right)$ without a Cav $\beta$ subunit. We observed small barium currents (current density $=7.83 \pm 1.15 \mathrm{pA} \mathrm{pF}^{-1}$, $n=47)$ in the absence of $\operatorname{Cav} \beta$, as reported ${ }^{28}$. Coexpression of DNRFP2 increased Cav1.2 peak current density to $17.16 \pm 2.56 \mathrm{pA} \mathrm{pF}^{-1}$ ( $n=42, P=0.001$ ) which fits with the biochemical analysis of Figure 1c. Together, these data show that interfering with RFP2-mediated ubiquitination of Cav1.2 channels increases the functional expression of these channels in the cell membrane.

We then examined the role of RFP2 in cultured rat hippocampal neurons. Neurons were transfected with HA-Cav1.2 with or without cotransfection of WT- or DN-RFP2 ligase. Live cells were incubated with HA antibody without permeabilization before fixation, allowing us to analyze the distribution of Cav1.2 channels on the cell surface (Fig. 7b-d). Expression of HA-Cav1.2 channels resulted in the appearance of discrete puncta along axonal and dendritic processes (Fig. $\mathbf{7 b}, \mathbf{c}$ ), consistent with the association of a fraction of the expressed channels with endogenous Cav $\beta$ subunits. In cells that coexpressed DN-RFP2 (Fig. 7d) there was a statistically significant increase in the numbers of HA-Cav1.2 puncta per $\mu \mathrm{m}$ (from $2.25 \pm 0.24$ to $5.54 \pm 0.41, n=22$ and $n=26$, respectively; $P<0.01)$ and in overall HA-Cav1.2 cell surface expression (from $18.05 \pm 1.42$ to $32.57 \pm 1.13$ pixel intensity units per surface area, $n=39$ and $n=90$, respectively; $P<0.01)$ compared with cells expressing the WT-RFP2 construct. This fits with a mechanism by which DN-RFP2 results in the targeting of the excess HA-Cav1.2 channels that are not associated with endogenous $\operatorname{Cav} \beta$ subunits to the cell surface. Collectively, our data are consistent with the idea that RFP2 has an active role in regulating L-type channel membrane trafficking in neurons. Qualitatively similar results were obtained when we competitively uncoupled Cav $\beta$ subunits from Cav1.2 by overexpressing a construct corresponding to the I-II linker of the channel (Supplementary Fig. 8). Overall, several lines of evidence implicate RFP2 ubiquitin ligase as a regulator of Cav1.2 channel function and expression in both heterologous expression systems and native tissues.

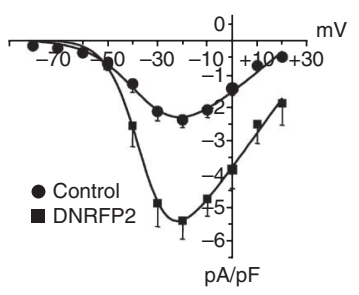

C

HA-Cav1.2 + WT-RFP2

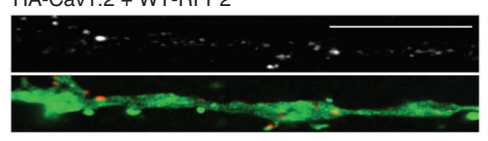

d

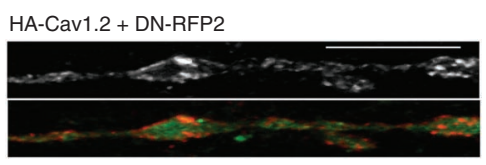

b
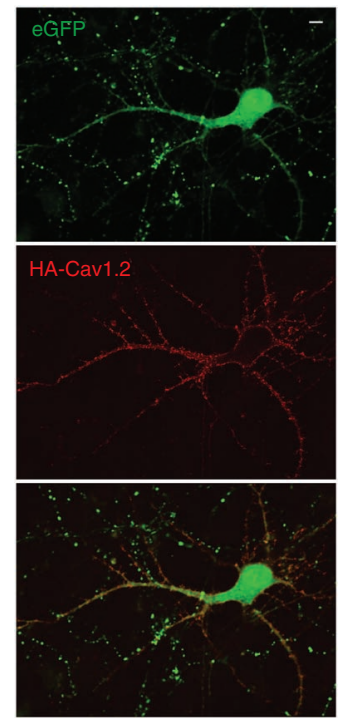

\section{DISCUSSION}

The role of the Cav $\beta$ subunit in enhancing cell surface levels of HVA channels is well established, but how this regulation occurs at the molecular level has remained largely unknown. Here, we provide insights into the cell signaling pathways that regulate the plasma membrane density of Cav1.2 L-type channels. Our data show that the Cav $\beta$ subunit controls a sorting step in the endoplasmic reticulum that diverts channels from the ERAD complex to the cell surface (Supplementary Fig. 9). This may involve multiple Cav $\beta$ subunitdependent steps, including interference with an endoplasmic reticulum retention motif in the $\mathrm{C}$ terminus, occlusion of ubiquitination sites and perhaps preventing the association of the channel with ubiquitin ligase(s).

Our data indicate that different types of HVA channels have evolved different mechanisms by which the $\operatorname{Cav} \beta$ subunit regulates their export from the endoplasmic reticulum. First, compared with Cav1.2, Cav2.1 channels do not appear to undergo much ubiquitination in the absence of the $\operatorname{Cav} \beta$ subunit. Furthermore, in contrast with Cav1.2 and Cav2.2 channels, retention of Cav2.1 in the endoplasmic reticulum seems to be mediated by the domain I-II linker rather than the $\mathrm{C}$-terminal region. This suggests that Cav2.1 channels use an endoplasmic reticulum export pathway that is different from that used by L-and N-type channels. Second, although Cav1.2 and Cav2.2 share overlapping endoplasmic reticulum retention motifs in the proximal $\mathrm{C}$ terminus region, Cav1.2 channels seem to contain a second, downstream endoplasmic reticulum retention motif that does not seem to be conserved in Cav2.2 channels (Supplementary Fig. 3). This redundancy might indicate a need to precisely control L-type channel expression for purposes such as calcium-dependent gene transcription ${ }^{2}$. Coexpression of the $\operatorname{Cav} \beta$ subunit did not alter retention of the Cav1.2 C terminus in the endoplasmic reticulum, but it mediated a marked increase in cell surface and total protein expression of the full-length channel. Even though the I-II linker itself does not seem to contain an endoplasmic reticulum retention motif, binding of the Cav $\beta$ subunit to this region is critical, because the W440A mutant abolishes not only Cav $\beta$ binding to the channel, but also its ability to promote L-type channel membrane expression ${ }^{25,26}$. All of these findings can be reconciled by a mechanism in which binding of the $\operatorname{Cav} \beta$ subunit to the I-II linker sterically or perhaps allosterically interferes 
with the recognition of the C-terminal region as an endoplasmic reticulum retention motif in a properly folded channel protein.

Our data pinpoint RFP2 ligase as a key element in regulating the ubiquitination and expression of the channel. RFP2 is expressed in a number of tissues, such as the heart and the brain, that also express L-type channels ${ }^{29}$. Originally identified as a tumor suppressor ${ }^{30}$, RFP2 was only recently shown to be a ring finger ubiquitin ligase that is involved in $\mathrm{ERAD}^{27}$. As a result, there has been little if any information on the physiological role of its ligase activity. Our data showing that RFP2 regulates ubiquitination and membrane expression of Cav1.2 provide a glimpse into its function in the mammalian nervous system. Furthermore, this is one of only a few examples, such as CFTR, where a specific ubiquitin ligase has been linked to ion channel regulation at the level of the endoplasmic reticulum.

We could observe Cav1.2 ubiquitination only in the presence of MG132, which indicates that ubiquitinated channels are rapidly transported to the proteasome for degradation. This proteasomal transport seems to be mediated by derlin-1 and p97, two members of the ERAD complex. This is not without precedent in ion channels. For example, a CFTR deletion mutant that is misfolded retrotranslocates via Derlin-1, and similar observations have been reported for KCa3.1 and KCa3.2 mutants ${ }^{21,31-33}$. However, Cav1.2 channels differ in that the degradation process is regulated by an ancillary channel subunit, so that the channel can be recognized by the ERAD complex as a misfolded protein in the absence of $\operatorname{Cav} \beta$. Hence, the Cav $\beta$ subunit is a key determinant of channel stability, by virtue of its ability to divert Cav1.2, and possibly other types of HVA calcium channel, from the ERAD pathway to their appropriate locale in the plasma membrane.

Our data indicate that there is a basal level of Cav1.2 channel ubiquitination in both CAD cells and hippocampal neurons that can be unmasked by blocking proteasomal degradation. This suggests that in these cells there may be an excess of calcium channel $\alpha_{1}$ subunits that could potentially be recruited upon increases in expression of the Cav $\beta$ subunit. There is evidence that Cav $\beta$ expression varies during neuronal development ${ }^{34}$, and is increased during pathophysiological conditions such as temporal lobe epilepsy ${ }^{35}$ and during heart failure ${ }^{36}$, when an increase in $C a v \beta_{2}$ subunits is mirrored by an increase in L-type channel density. Such findings fit with the idea that the cell surface density of calcium channels can be controlled by dynamic changes in ubiquitination that result from altered Cav $\beta$ expression.

Collectively, our findings reveal a bifurcation in the calcium channel export pathway from the endoplasmic reticulum, with a ubiquitin ligase and the $\operatorname{Cav} \beta$ subunit defining alternate routes. Our data provide insights into the fundamental mechanisms of calcium channel sorting and trafficking, with potentially broad implications for a wide range of excitable cells.

\section{METHODS}

Methods and any associated references are available in the online version of the paper at http://www.nature.com/natureneuroscience/.

Note: Supplementary information is available on the Nature Neuroscience website.

\section{ACKNOWLEDGMENTS}

We thank J. Striessnig, S. Ferguson, J. Stutts, B. Schwappach, E. Bourinet and T. Snutch for cDNA constructs, and E. Stanley for help with the ICQ colocalization analysis. This work was supported by operating grants to G.W.Z. from the Heart and Stroke Foundation of Alberta, the Northwest Territories and Nunavut, and the Canadian Institutes for Health Research. G.W.Z. is a Scientist of the Alberta Heritage Foundation for Medical Research (AHFMR) and a Canada
Research Chair in Molecular Neurobiology. H.Y. is supported by an AFHMR fellowship and B.S. is supported by an AHFMR studentship.

\section{AUTHOR CONTRIBUTIONS}

C.A., A.G.-C. and G.W.Z. designed the study and wrote the manuscript. G.W.Z. supervised the study. C.A., A.G.-C., B.S., H.Y. and L.C. performed experiments and data analysis. J.W. and H.W.T. contributed to molecular biology.

\section{COMPETING FINANCIAL INTERESTS}

The authors declare no competing financial interests.

Published online at http://www.nature.com/natureneuroscience/.

Reprints and permissions information is available online at http://www.nature.com/ reprintsandpermissions/.

1. Berridge, M.J., Bootman, M.D. \& Roderick, H.L. Calcium signaling: dynamics, homeostasis and remodeling. Nat. Rev. Mol. Cell Biol. 4, 517-529 (2003).

2. Dolmetsch, R.E., Pajvani, U., Fife, K., Spotts, J.M. \& Greenberg, M.E. Signaling to the nucleus by an L-type calcium channel-calmodulin complex through the MAP kinase pathway. Science 294, 333-339 (2001).

3. Catterall, W.A., Perez-Reyes, E., Snutch, T.P. \& Striessnig, J. International Union of Pharmacology. XLVIII. Nomenclature and structure-function relationships of voltage-gated calcium channels. Pharmacol. Rev. 57, 411-425 (2005).

4. Birnbaumer, $L$. et al. Structures and functions of calcium channel beta subunits. J. Bioenerg. Biomembr. 30, 357-375 (1998).

5. Dolphin, A.C. Beta subunits of voltage-gated calcium channels. J. Bioenerg Biomembr. 35, 599-620 (2003).

6. Hidalgo, P. \& Neely, A. Multiplicity of protein interactions and functions of the voltage-gated calcium channel beta-subunit. Cell Calcium 42, 389-396 (2007).

7. Pragnell, M. et al. Calcium channel beta-subunit binds to a conserved motif in the I-II cytoplasmic linker of the alpha 1-subunit. Nature 368, 67-70 (1994).

8. Opatowsky, Y., Chen, C.C., Campbell, K.P. \& Hirsch, J.A. Structural analysis of the voltage-dependent calcium channel beta subunit functional core and its complex with the alpha 1 interaction domain. Neuron 42, 387-399 (2004).

9. Chen, Y.H. et al. Structural basis of the alpha1-beta subunit interaction of voltagegated $\mathrm{Ca}^{2+}$ channels. Nature 429, 675-680 (2004).

10. Van Petegem, F., Clark, K.A., Chatelain, F.C. \& Minor, D.L. Jr. Structure of a complex between a voltage-gated calcium channel beta-subunit and an alpha-subunit domain. Nature 429, 671-675 (2004)

11. Gregg, R.G. et al. Absence of the beta subunit (cchb1) of the skeletal muscle dihydropyridine receptor alters expression of the alpha 1 subunit and eliminates excitation-contraction coupling. Proc. Natl. Acad. Sci. USA 93, 13961-13966 (1996).

12. Weissgerber, P. et al. Reduced cardiac L-type $\mathrm{Ca}^{2+}$ current in $\mathrm{Ca}(\mathrm{V})$ beta2 ${ }^{-1-}$ embryos impairs cardiac development and contraction with secondary defects in vascular maturation. Circ. Res. 99, 749-757 (2006).

13. Burgess, D.L., Jones, J.M., Meisler, M.H. \& Noebels, J.L. Mutation of the $\mathrm{Ca}^{2+}$ channel beta subunit gene Cchb4 is associated with ataxia and seizures in the lethargic (Ih) mouse. Cell 88, 385-392 (1997).

14. Bichet, D. et al. The I-II loop of the $\mathrm{Ca}^{2+}$ channel alphal subunit contains an endoplasmic reticulum retention signal antagonized by the beta subunit. Neuron 25 177-190 (2000)

15. Maltez, J.M., Nunziato, D.A., Kim, J. \& Pitt, G.S. Essential Ca(V)beta modulatory properties are AID-independent. Nat. Struct. Mol. Biol. 12, 372-377 (2005).

16. Zerangue, N., Schwappach, B., Jan, Y.N. \& Jan, L.Y. A new ER trafficking signal regulates the subunit stoichiometry of plasma membrane K(ATP) channels. Neuron 22, 537-548 (1999).

17. Zerangue, N. et al. Analysis of endoplasmic reticulum trafficking signals by combinatorial screening in mammalian cells. Proc. Natl. Acad. Sci. USA 98 2431-2436 (2001).

18. Römisch, K. Endoplasmic reticulum-associated degradation. Annu. Rev. Cell Dev. Biol. 21, 435-456 (2005).

19. Lilley, B.N. \& Ploegh, H.L. A membrane protein required for dislocation of misfolded proteins from the ER. Nature 429, 834-840 (2004).

20. Ye, Y., Shibata, Y., Yun, C., Ron, D. \& Rapoport, T.A. A membrane protein complex mediates retro-translocation from the ER lumen into the cytosol. Nature 429, 841-847 (2004)

21. Sun, F. et al. Derlin-1 promotes the efficient degradation of the cystic fibrosis transmembrane conductance regulator (CFTR) and CFTR folding mutants. J. Biol. Chem. 281, 36856-36863 (2006).

22. Tsai, B., Ye, Y. \& Rapoport, T.A. Retro-translocation of proteins from the endoplasmic reticulum into the cytosol. Nat. Rev. Mol. Cell Biol. 3, 246-255 (2002).

23. Abriel, H. \& Staub, O. Ubiquitylation of ion channels. Physiology (Bethesda) 20, 398-407 (2005). 


\section{ARTICLES}

24. Obermair, G.J. et al. Reciprocal interactions regulate targeting of calcium channel beta subunits and membrane expression of alpha1 subunits in cultured hippocampal neurons. J. Biol. Chem. 285, 5776-5791 (2010).

25. Leroy, J. et al. Interaction via a key tryptophan in the I-II linker of N-type calcium channels is required for beta1 but not for palmitoylated beta2, implicating an additional binding site in the regulation of channel voltage-dependent properties. J. Neurosci. 25, 6984-6996 (2005).

26. Deshaies, R.J. \& Joazeiro, C.A. RING domain E3 ubiquitin ligases. Annu. Rev. Biochem. 78, 399-434 (2009).

27. Lerner, $M$, et al. The RBCC gene RFP2 (Leu5) encodes a novel transmembrane E3 ubiquitin ligase involved in ERAD. Mol. Biol. Cell 18, 1670-1682 (2007).

28. Yasuda, T. et al. Auxiliary subunit regulation of high-voltage activated calcium channels expressed in mammalian cells. Eur. J. Neurosci. 20, 1-13 (2004).

29. Baranova, A. et al. Distinct organization of the candidate tumor suppressor gene RFP2 in human and mouse: multiple mRNA isoforms in both species- and humanspecific antisense transcript RFP20S. Gene 321, 103-112 (2003).

30. Corcoran, M.M. et al. DLEU2 encodes an antisense RNA for the putative bicistronic RFP2/LEU5 gene in humans and mouse. Genes Chromosom. Cancer 40, 285-297 (2004).
31. Younger, J.M. et al. Sequential quality-control checkpoints triage misfolded cystic fibrosis transmembrane conductance regulator. Cell 126, 571-582 (2006)

32. Wang, B. et al. BAP31 interacts with Sec61 translocons and promotes retrotranslocation of CFTRDeltaF508 via the derlin-1 complex. Cell 133, 1080-1092 (2008).

33. Gao, Y. et al. Role of S3 and S4 transmembrane domain charged amino acids in channel biogenesis and gating of KCa2.3 and KCa3.1. J. Biol. Chem. 283, 9049-9059 (2008).

34. Vance, C.L. et al. Differential expression and association of calcium channel alpha1B and beta subunits during rat brain ontogeny. J. Biol. Chem. 273, 14495-14502 (1998).

35. Lie, A.A. et al. Distribution of voltage-dependent calcium channel beta subunits in the hippocampus of patients with temporal lobe epilepsy. Neuroscience 93, 449-456 (1999).

36. Hullin, R. et al. Increased expression of the auxiliary beta2-subunit of ventricular L-type $\mathrm{Ca}^{2+}$ channels leads to single-channel activity characteristic of heart failure. PLOS ONE 2, e292 (2007). 


\section{ONLINE METHODS}

Cell culture and transfection. Human embryonic kidney tsA-201 cells were cultured as described ${ }^{37}$. Cells were transfected with calcium phosphate and used for biochemical and electrophysiological analysis $72 \mathrm{~h}$ (for Cav1.2 channel) and $48 \mathrm{~h}$ (for CD4 constructs) after transfection.

Plasmid preparation. The HA-tagged Cav1.2 construct was generated by inserting an HA epitope into the extracellular S5-H5 loop of domain II as described ${ }^{38}$. HA-Cav1.2 ${ }_{\text {W440A }}$ was generated by PCR mutagenesis. HA-Cav2.1 cDNA was a gift from J. Striessnig. Rab-GFP constructs were provided by S. Ferguson. Cav1.2, Cav2.2 and Cav2.1 intracellular linkers were amplified by PCR and subcloned in frame into human CD4 pCDNA3.1 vector (gift from B. Schwappach). $\operatorname{Cav} \beta_{1 b}$ and $\operatorname{Cav} \beta_{2 a}$ subunits were PCR amplified and subcloned into the N1-YFP vector (Clontech). Flag-tagged $\operatorname{Cav} \beta_{2 a}$ was provided by J.D. Spafford. Xpress-tagged ubiquitin pcDNA3.1 vector was a gift from J. Stutts. Wild-type Cav1.2 subunit cDNAs were provided by T. Snutch. Wild-type and dominant-negative RFP2 (Genescript) were subcloned into N1-YFP vector (Clontech). DN-RFP2 lacks the first 131 amino acid residues where the RING domain is located and was made by inserting a start codon at residue 131. RFP2, GP78 and HRD1 shRNA plasmids were purchased from Santa Cruz Biotechnology, Inc.

Surface labeling. tsA-201 cells were transiently transfected with similar amounts of DNA (20 $\mu$ g per 10-cm dish): HA-Cav1.2, $\operatorname{Cav} \alpha_{2}-\delta_{1}, \operatorname{Cav} \beta_{1 b}, \operatorname{Cav} \beta_{2 a}$ or empty vector pcDNA3.1. Cells were pre-chilled on ice for $30 \mathrm{~min}$ and labeled with $1 \mathrm{mg} \mathrm{m}^{-1}$ sulfo-NHS-biotin in PBS-Ca-Mg (mM), $1 \mathrm{MgCl} 2,0.1 \mathrm{CaCl} 2$, titrated to $\mathrm{pH} 8.3$ with $\mathrm{NaOH}$, while tumbling gently for $30 \mathrm{~min}$ at $4{ }^{\circ} \mathrm{C}$. Cells were washed twice with chilled PBS-Ca-Mg buffer and incubated in PBS-Ca-Mg buffer with $100 \mathrm{mM}$ glycine for $10 \mathrm{~min}$ at $4{ }^{\circ} \mathrm{C}$ to quench free biotin. Cells were washed again three times with chilled PBS-Ca-Mg buffer, then lysed with lysis buffer (in mM; 50 Tris, $100 \mathrm{NaCl}, 1 \%$ triton X-100 (vol/vol), $1 \% \mathrm{NP}-40$ (vol/vol), $0.2 \% \mathrm{SDS}$ (wt/vol), $0.1 \%$ $\mathrm{NaDeoxycholate}$ (wt/vol), $20 \mathrm{NaF}, 10 \mathrm{Na}_{4} \mathrm{P}_{2} \mathrm{O}_{7}$ pyrophosphate, $10 \mathrm{EDTA}$ + protease inhibitor cocktail (complete, Roche), pH 7.5). Cell lysates were prepared by sonicating samples at $60 \%$ pulse for $10 \mathrm{~s}$ and by centrifugation at $14,000 \mathrm{rpm}$ for $15 \mathrm{~min}$ at $4{ }^{\circ} \mathrm{C}$. Supernatants were transferred to new tubes and solubilized proteins were incubated with $70 \mu \mathrm{l}$ of neutravidin beads (Pierce) overnight while tumbling at $4{ }^{\circ} \mathrm{C}$. Total inputs were taken from whole cell samples representing $4 \%$ of total protein. Samples were washed twice with $(\mathrm{mM}) 500 \mathrm{NaCl}, 50$ Tris $\mathrm{pH} 7.5$ buffer and once with $150 \mathrm{NaCl}, 50$ Tris $\mathrm{pH} 7.5$ buffer. Laemmli buffer was added and samples were loaded on an $8 \%$ Tris-glycine gel after incubation for $10 \mathrm{~min}$ at $96^{\circ} \mathrm{C}$. Samples were transferred to $0.45 \mu \mathrm{m}$ polyvinylidene difluoride (PDVF) membranes (Millipore) and western blot analysis was performed using an anti-HA antibody (Covance).

Immunoprecipitation and co-immunoprecipitation assays. Cells were lysed RIPA buffer (in mM; 50 Tris, $100 \mathrm{NaCl}, 1 \%$ triton X-100, 1\% NP-40, 0.2\% SDS, $0.1 \%$ NaDeoxycholate, $20 \mathrm{NaF}, 10 \mathrm{Na}_{4} \mathrm{P}_{2} \mathrm{O}_{7}$ pyrophosphate, $10 \mathrm{EDTA}$ + protease inhibitor cocktail, pH 7.5). A modified RIPA buffer (in mM; 50 Tris, $100 \mathrm{NaCl}$, $0.2 \%$ triton X-100, $0.2 \%$ NP-40, 10 EDTA + protease inhibitor cocktail, with or without $5 \mu \mathrm{M}$ MG132 $\mathrm{pH}$ 7.5) was used to co-immunoprecipitate calcium channel subunits. Lysates from tsA-201 cells, CAD cells and rat brain tissue were prepared by sonicating samples at $60 \%$ pulse for $10 \mathrm{~s}$ and by centrifugation at $13,000 \mathrm{rpm}$ for $15 \mathrm{~min}$ at $4{ }^{\circ} \mathrm{C}$. Supernatants were transferred to new tubes and solubilized proteins were incubated with $50 \mu \mathrm{l}$ of Protein G/A beads (Pierce) and $1 \mu \mathrm{g}$ of HA antibody (Roche) or $2 \mu \mathrm{g}$ of Cav1.2 antibody (Alomone and NeuroMab) or $2 \mu \mathrm{g}$ of RFP2 antibody (Santa Cruz Biotechnologies, Inc.) overnight while tumbling at $4{ }^{\circ} \mathrm{C}$. Total inputs were taken from whole cell samples representing $4 \%$ of total protein and probed for actin. Immunoprecipitates were washed twice with $(\mathrm{mM}) 500 \mathrm{NaCl}, 50$ Tris $\mathrm{pH} 7.5$ buffer and once with $150 \mathrm{NaCl}, 50$ Tris pH 7.5 buffer; co-immunoprecipitates were extensively washed with modified RIPA buffer and beads were aspirated to dryness. Laemmli buffer was added and samples were incubated at $96^{\circ} \mathrm{C}$ for $7 \mathrm{~min}$. Eluted samples were loaded on an $8 \%$ or $10 \%$ Tris-glycine gel and resolved using SDS-PAGE. Samples were transferred to $0.45 \mu \mathrm{m}$ PDVF membranes (Millipore) and western blot analysis was performed using anti-HA (Covance), anti-ubiquitin FK2 (Biomol), anti Cav1.2 (Alomone), anti-ubiquitin (BD Pharmingen), anti-actin (Sigma), anti-derlin-1 (Sigma), anti-RFP2 (Santa Cruz Biotechnologies, Inc.) and anti-p97 (Abcam) antibodies. Some western blot images were cropped owing to space limitations. Full-length versions of the most important blots are shown in Supplementary Figure 10.
Imaging of rat hippocampal neurons and tsA-201 cells. Hippocampal neurons were dissociated as described for cortical neurons ${ }^{39}$ and seeded at low density onto coverslips pretreated with poly-D-lysine (Sigma) followed by Laminin (Sigma) in 24-well plates. At day six of culture, transfection of cDNA was performed using Lipofectamine 2000 (Invitrogen) following the manufacturer's instructions. We used $1.5 \mu \mathrm{g}$ of cDNA per well (ratio HA-Cav1.2:RFP2:GFP = 2:1:1) with $2 \mu \mathrm{l}$ of Lipofectamine. cDNA and Lipofectamine solution were mixed together for $30 \mathrm{~min}$ at room temperature. Cells were incubated in cDNA-lipofectamine 2000 complexes for $2 \mathrm{~h}$ at $37^{\circ} \mathrm{C}$ and coverslips were placed back in their medium. Four days after transfection, live immunostaining with $\mathrm{HA}$ antibody (1:500, $30 \mathrm{~min})$ was conducted at $37^{\circ} \mathrm{C}^{24}$. Then, cells were washed and fixed in $4 \%$ paraformaldehyde $+4 \%$ sucrose for $10 \mathrm{~min}$. Alexa Fluor 596-conjugated goat $\alpha$-rat IgG antibody (Molecular Probes, 1:1,000) was used as secondary antibody.

Cultured tsA-201 cells were transiently transfected. Seventy two hours (for HA-Cav1.2) or fourty eight hours after transfection, cells were fixed with $4 \%$ paraformaldehyde, either permeablized with $0.5 \%$ triton-X-100 (in PBS) or not, and immunostained with anti-HA (1:1,000, Roche) or anti-CD4 (1:1,000, eBioscience) antibodies. Alexa Fluor 488-conjugated goat $\alpha$-mouse IgG antibody (Molecular Probes, 1:1,000) or Alexa Fluor 594-conjugated goat $\alpha$-rat IgG antibody (Molecular Probes, 1:1,000) were used for CD4 and HA, respectively.

Cells were imaged using a Zeiss LSM-510 Meta confocal microscope with a $63 \times 1.4 \mathrm{NA}$ oil immersion lens in the inverted position. EYFP was visualized by excitation with an argon laser $(514 \mathrm{~nm}$ ) and emission detected using a long-pass 530-nm filter. AF-568 antibody was visualized by excitation with a HeNe laser $(543 \mathrm{~nm})$ and emission detected using a 560-615-nm bandpass filter. AF-594 antibody was visualized by excitation with a HeNe laser $(543 \mathrm{~nm})$ and emission detected using a 585-615-nm bandpass filter. Image acquisition was performed with identical gain, contrast, laser excitation, pinhole aperture and laser scanning speed for each round of cultures. Analysis of puncta was done following threshold adjustment with Image J.

Colocalization analysis. Colocalization data were calculated using an image J algorithm that was developed in the laboratory of E. Stanley (University of Toronto $)^{40}$. Briefly, confocal images were threshold corrected and for each image the threshold was adjusted to the onset of the histogram of the frequency of staining intensities. Intensity Correlation Analysis was performed as described ${ }^{40}$. Each image was background subtracted. Based on the algorithm, in an image where the intensities vary together, the product of the differences from the mean (PDM) will be positive. If the pixel intensities vary asynchronously (the channels are segregated so that when a red pixel is above average and a corresponding green pixel is below average) then most of the PDM will be negative. The Intensity Correlation Quotient (ICQ) is based on the non-parametric sign-test analysis of the PDM values and is equal to the ratio of the number of positive PDM values to the total number of pixel values. The ICQ values are distributed between -0.5 and +0.5 by subtracting 0.5 from this ratio. Random staining: ICQ $\approx 0$; segregated staining: $0>\mathrm{ICQ} \geq-0.5$; dependent staining: $0<\mathrm{ICQ} \leq+0.5$.

Cell surface immunoluminometry assays. Cultured tsA-201 cells were transiently transfected with HA-Cav1.2 (with or without $\operatorname{Cav} \beta$ ) or with CD4 constructs. Cells were incubated at $37^{\circ} \mathrm{C}$ for $24 \mathrm{~h}$, trypsinized, and re-seeded in triplicate onto poly-L-lysine-coated coverslips. Cells were then incubated for $24 \mathrm{~h}$ for $\mathrm{CD} 4$ and $48 \mathrm{~h}$ for HA-Cav 1.2 at $37^{\circ} \mathrm{C}$. All cells were subsequently washed with $\mathrm{PBS}$, and fixed with $4 \%$ paraformaldehyde (5 min, room temperature). At this stage, a replicate ( 3 coverslips) from each condition was permeablized ( $7 \mathrm{~min}$ ) by the addition of $0.5 \%$ triton-X-100 to the pre-blocking solution. Cells were then pre-blocked for $30 \mathrm{~min}$ in PBS containing 2\% FBS. Cells were incubated in antiHA antibody (1:800, Roche) in PBS $+2 \%$ goat serum for $1 \mathrm{~h}$. Cells were washed $(3 \times 10 \mathrm{~min})$ in PBS $+2 \%$ serum, and incubated in HRP-conjugated goat antirat IgG antibody (1:1,000, Jackson ImmunoResearch Laboratories) for $30 \mathrm{~min}$ at room temperature. Cells were subsequently washed $3 \times 20 \mathrm{~min}$ in PBS $+2 \%$ serum, and $1 \times 20 \mathrm{~min}$ in PBS. Single coverslips were transferred to a 24-well, white-bottomed microtiter plate in which $200 \mu \mathrm{l}$ of Supersignal ELISA Femto Maximum Sensitivity Substrate (Pierce) had been placed. The luminometry signal was read using a Mithras Microplate Reader LB 940 from BERTHOLD technologies. As the HA-tag on the Cav1.2 channel construct is extracellular, signal intensity from nonpermeabilized cells was used as a measure of channel surface expression, and signal intensity from permeabilized cells was used as 
a measure of total cellular channel expression. The ratio of cell surface to total cellular channel expression allowed comparisons between various conditions assayed from different batches of cells. In case of the CD4 constructs, the ratio of surface signal of luminescence to total signal of luminescence which represents the surface expression was normalized to the positive control (CD4-AA; Fig. 2c,d and Supplementary Fig. 4b). As we used transient transfection that can cause different levels of expression and slight differences in the luminescence signal, this normalization allowed us to compare data from different cell batches.

Electrophysiology. Whole-cell voltage-clamp recordings for tsA-201 cells and $\mathrm{CAD}$ neurons were performed $72 \mathrm{~h}$ after transfection. We used $7 \mu \mathrm{g}$ of cDNA for transfection of tsA-201 cells (Cav1.2 or Cavo $\alpha_{2}-\delta_{1}(2 \mu \mathrm{g})$; GFP $(0.5 \mu \mathrm{g})$ and WT- or DN-RFP2 $(2 \mu \mathrm{g}))$. For CAD cells, Cav1.2 and Cavo $\alpha_{2}-\delta_{1}$ were omitted. Recordings were conducted with $20 \mathrm{mM}$ barium as the charge carrier, using internal and external recording solutions as described ${ }^{39}$. Currents were elicited from a holding potential of $-100 \mathrm{mV}$ and depolarized from -70 to $+50 \mathrm{mV}$ with $10-\mathrm{mV}$ increments. Data were collected from multiple batches of transfections with similar numbers of cells tested from the different groups (control, WTRFP2 and DN-RFP2). For data analysis, peak currents and cell capacitance were measured and converted into current density.

Statistical analysis. Statistical analysis was conducted by $t$-tests or one-way analysis of variance (ANOVA) followed by Tukey's multiple comparison tests. Statistical significance was set at $P<0.05$, and all error bars represent s.e.m.

37. Altier, C. et al. ORL1 receptor-mediated internalization of $\mathrm{N}$-type calcium channels. Nat. Neurosci. 9, 31-40 (2006).

38. Altier, C. et al. Trafficking of L-type calcium channels mediated by the postsynaptic scaffolding protein AKAP79. J. Biol. Chem. 277, 33598-33603 (2002).

39. Kisilevsky, A.E. et al. D1 receptors physically interact with $\mathrm{N}$-type calcium channels to regulate channel distribution and dendritic calcium entry. Neuron 58, 557-570 (2008).

40. Li, Q. et al. A syntaxin 1, Galpha(o), and N-type calcium channel complex at a presynaptic nerve terminal: analysis by quantitative immunocolocalization. J. Neurosci. 24, 4070-4081 (2004). 